incremental seniority via standardised reviews based on the appraisal process. Committee and managerial work should be allocated additional sessions, openly assessed and competed for and again acknowledged via seniority. Loyalty of service - it takes years to generate an effective knowledge of locality and networks - should also be acknowledged to counter the disheartening spectacle of locums being paid more than committed 'regulars'. We admire the dedication and care of all those involved in trying to help develop scoring and assessment systems for these awards, but our own view remains that the aftermath is always one of a sense of embarrassment, depression and pervasive ennui.

*TrevorTurner Consultant Psychiatrist, Clinical Director, Homerton University Hospital,

Michael Maier Senior Lecturer, Honorary Consultant Psychiatrist, West London Mental Health NHS Trust, Uxbridge Road, Southall, Middlesex UB1 3EU

\section{Venlafaxine discontinuation symptoms on prolonged low dose}

The National Institute for Clinical Excellence guidelines state that all patients prescribed antidepressants should be informed that, although the drugs are not associated with tolerance and craving, discontinuation/withdrawal symptoms may occur on stopping, missing doses or occasionally, on reducing the dose of the drug. These symptoms are usually mild and self-limiting, but can occasionally be severe, particularly if the drug is stopped abruptly.

Discontinuation symptoms are commonly described in patients taking venlafaxine (Pinzani et al, 2000; Baboolal,
2004). Shock-like sensation has been described with the discontinuation of venlafaxine (Reeves et al, 2003) and more often with the discontinuation of selective serotonin reuptake inhibitors (SSRIs) (Black et al, 2000). This case differs from others because the patient was taking a sub-therapeutic dose and the duration of the discontinuation symptoms was longer.

A 41-year-old research scientist with a 15-year history of bipolar affective disorder has been treated successfully with $600 \mathrm{mg}$ lithium and venlafaxine since 1995 when he had a manic episode followed by a depressive episode. He has adhered well to his repeat prescriptions and he has remained euthymic. His lithium blood levels have remained stable and within the therapeutic range.

After 5 years in remission the dose was decreased to $50 \mathrm{mg}$ without any problems, but when trying to stop it he would always experience discontinuation symptoms hours after missing the dose. Five years later it was decided not to issue the prescription because the dose was no longer available.

From the morning after missing his usual night-time dose, he started to experience shock-like sensations, described as 'electric shocks with a loud noise in my brain', every few minutes, irritability, emotional lability, poor concentration, dyskinesia in the form of sudden uncontrollable body movements, dry mouth, 'tannin-like' taste in the mouth, profuse sweating and insomnia. He was unable to work or drive. The symptoms improved on the fifth day, but continuing poor concentration and shock-like sensations rendered him unable to resume his normal activities. On the tenth day, his concentration was still poor and the shock-like sensations were occurring a few times a day. By then his emotional lability had resolved but the dyskinesia persisted. From the tenth day all remaining symptoms resolved with a transient recurrence of electric shock sensations up to day 17. He was then able to return to work and to drive. He has remained well since.

Discontinuation symptoms with venlafaxine are similar to those with SSRIs and it is very likely that the serotonin transmitter system is involved. A UK survey (Young \& Currie, 1997) has shown that too few consultant psychiatrists and general practitioners are aware of discontinuation symptoms of antidepressants. Venlafaxine should be gradually tapered and the patient should be informed of the potential physical and psychological disturbances abrupt discontinuation can cause.

BABOOLAL, N. S. (2004) Venlafaxine withdrawal syndrome: report of seven cases inTrinidad. Journal of Clinical Psychopharmacology, 24, 229-231.

BLACK, K., SHEA, C., DURSUN, S., et al (2000) Selective serotonin reuptake inhibitor discontinuation syndrome: proposed diagnostic criteria. Journal of Psychiatry and Neuroscience, 25, 255-261.

PINZANI, V., GINIES, E., ROBERT, L., et al (2000) Venlafaxine withdrawal syndrome: report of six cases and review of the literature. Revue de Médecine Interne, 21, 282-284.

REEVES, R. R., MACK, J. E. \& BEDDINGFIELD, J. J. (2003) Shock-like sensations during venlafaxine withdrawal. Pharmacotherapy, 23, 678-681.

YOUNG, A. H. \& CURRIE, A. (1997) Physicians knowledge of antidepressant withdrawal effects: a survey. Journal of Clinical Psychiatry, 58 (suppl. 7), $28-30$

Sophie Dechene Senior House Officer, Merseycare, Liverpool, e-mail: sdechene@ doctors.net.uk 